\title{
High Precision Strain Gauge Based Sensor for Monitoring Suspension Forces at CERN
}

\author{
Friedrich Lackner, Werner Riegler, P. Herbert Osanna ${ }^{1}$, M. Numan Durakbasa ${ }^{1}$ \\ CERN, European Organisation for Nuclear Research, CH-1211 Geneva-23, Switzerland \\ ${ }^{1}$ Interchangeable Manufacturing and Industrial Metrology, \\ Vienna University of Technology (TUW), Karlspl. 13/3113, A-1040 Vienna, Austria \\ Email: Friedrich.Lackner@cern.ch
}

\begin{abstract}
At the end of 2007, the world's largest particle accelerator, the LHC (Large Hadron Collider), will be ready to collide first particles. Protons will be accelerated in a ring of $27 \mathrm{~km}$ circumference, contained inside an evacuated pipe of $60 \mathrm{~mm}$ diameter. At four interaction points, where the large particle detectors are placed, this beampipe is made from beryllium in order to limit the multiple scattering of particles on their way from the interaction point to the detector. In order to keep the sag in the pipe to acceptable levels, accurate monitoring of the forces in the cables, which hold the beryllium beampipe in place, is required. The beampipe is installed in an environment of $0.5 \mathrm{~T}$ magnetic field and is expected to absorb a dose of 1 Mrad in ten years. These special constraints and the lack of accessibility preclude most standard monitoring systems. Previous work has shown that strain gauge based systems work well under the described conditions. This report shows that the monitoring system for the ALICE beryllium beampipe requires a minimum sensor size which results in $\mu \mathrm{V}$ effective range for the signal. The device provides the requested resolution of $1 \mathrm{~N}$.
\end{abstract}

Keywords: Strain gauge, suspension force, beampipe monitoring

\section{INTRODUCTION}

$\mathrm{O}_{1}$ NE of the four LHC experiments is ALICE, short for "A Large Ion-Colliding-Experiment", a detector consisting of multiple layers of subdetectors around the collision point to detect different types and properties of particles created in the collisions [1] [3] [4]. Those particles are identified via their energy, momentum, path, and decay products. The evacuated central beryllium beampipe with a length of $4600 \mathrm{~mm}$ and a diameter of $60 \mathrm{~mm}$ is supported in three points. Two of those support points (see Fig. 1 support B and $\mathrm{C}$ ) allow rotations transverse to the beam axis. At points $\mathrm{B}$ and $\mathrm{C}$ stainless steel wire ropes are used to hold the beampipe in place. The third point $(\mathrm{C})$ is designed as a fixed bearing point in order to compensate the vacuum force which results in an axial thrust of $50 \mathrm{~kg}$. The desired effect of the 'theoretical' fixation point is given in a small clearance resulting in a freedom of degree for small rotations [2]. This necessity is given by the required beampipe adjustments during the critical final integration of the ALICE TPC (Time Protection Chamber) and the ITS (Inner Tracking System) detector [2] [6].

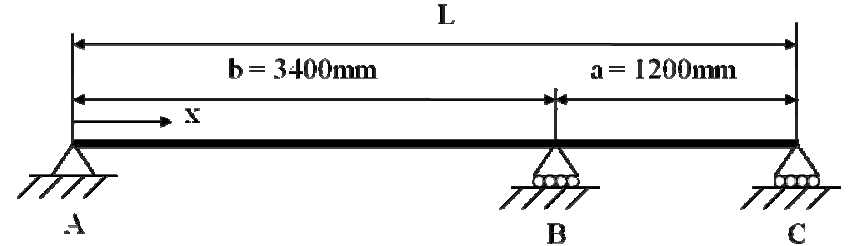

Fig. 1. Principle of the beampipe support
The permissible stress for the beryllium beampipe is equal to $15 \mathrm{~N} / \mathrm{mm}^{2}$, which is equivalent to a force of $42 \mathrm{~N}$ on the middle support. This force would result in a beampipe sag of $\mathrm{w}_{\mathrm{m}}=1.8 \mathrm{~mm}$ (Eq. 1). The position with the maximum sag, $\mathrm{x}_{\mathrm{m}}$, is given by Eq. 2 .

$$
\begin{gathered}
w_{m}=\frac{F L^{2} a}{4 E I_{y}}\left[\left(1-\frac{a^{2}}{L^{2}}\right)\left(\frac{x_{m}}{L}\right)^{2}-\left(1-\frac{a^{2}}{3 L^{2}}\right)\left(1-\frac{x_{m}}{L}\right)^{3}\right] \\
x_{m}=\frac{b\left(1+\frac{L}{a}\right)}{1+\frac{3 b}{2 a}+\frac{b}{2 L}}
\end{gathered}
$$

Different measurement systems are required to provide accurate online monitoring of the critical integration in order not to exceed the maximum deformation. The physical constraints preclude monitoring of force in all of the three beampipe supports. The only support acceptable for accurate force monitoring is support $\mathrm{B}$. Therefore, the pretension forces of $50 \mathrm{~N}$ in the four steel wires are monitored by installing sensor probes in each cable. The additional optical monitoring systems will provide the information of the ITS position during the critical movement of the TPC into the final position [1]. The output information of the different monitoring systems is providing accurate information about the position of the beampipe. 


\section{THE GAUGE BASED SENSOR DESIGN}

Different physical constraints preclude most standard sensorbased monitoring systems. In order to achieve the requirements, a new sensor design was necessary. Based on the design of tensile specimens, a small tube made from an AlMgSil alloy was designed as a substrate for applying a gauge full bridge (see Fig. 2). In order to minimize curvatureinduced change in the thermal output, the minimal acceptable diameter was $10 \mathrm{~mm}[8]$.
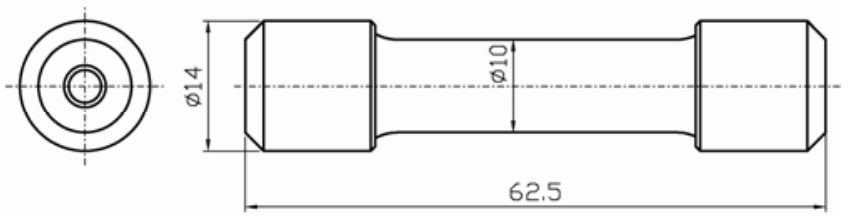

Fig. 2 Main dimensions of the $\mathrm{Al}$ specimens including the end caps

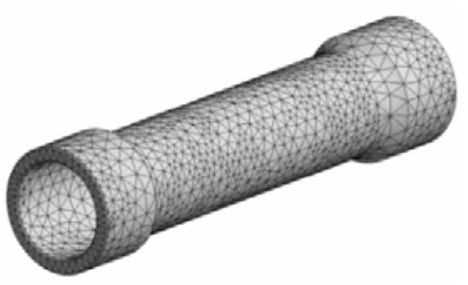

Fig. 3 ANSYS FEA probe model

Due to production limitations, finite element analyses were performed to improve the length - wall thickness proportion resulting in a maximum feasible readout resolution. As concerns the final design, this results in an expected readout resolution of better than $10 \mu \mathrm{V}$ per $1 \mathrm{~N}$ for wall thickness of $0.4 \mathrm{~mm}$ and an input voltage of $5 \mathrm{~V}$. The expected strain output in $\mu \varepsilon$ is shown in Fig. 4. The normalized output voltage is according to Eq. 3. [10] For the strain gage selection, two factors were taken in to account. The first factor was the gauge size which should be minimized in order to avoid curvature effects; the second one was the radiation hardness. As regards the radiation environment, the Los Alamos Scientific Laboratory has ascertained that strain gauges with a constantan grid encapsulated in polyamide can absorb a dose of min. $10^{11} \mathrm{rad}(1 \mathrm{rad}=0.01 \mathrm{Joules} / \mathrm{kg})$ [5]. The Vishay gauge - 032UW [9] with a grid size of $0.81 \times 1.52 \mathrm{~mm}$ and a gage factor of $K=2.1$ satisfies both of the main requirements and was therefore chosen for this application. The gauges are applied with the Vishay M-Bond 610 adhesive.

$$
\frac{U_{a}}{U_{\varepsilon}}=\frac{K}{4} N \varepsilon
$$

$\mathrm{K}$ Gage factor (VISHAY 032UW, $\mathrm{K}=2.1$ )

$\mathrm{N}$ Bridge factor $(\mathrm{N}=2.6$ full bridge connection on a hollow cylinder)

$\mathrm{U}_{\mathrm{a}}$ Output voltage

$\mathrm{U}_{\mathrm{e}}$ Input voltage

$\varepsilon \quad$ Strain

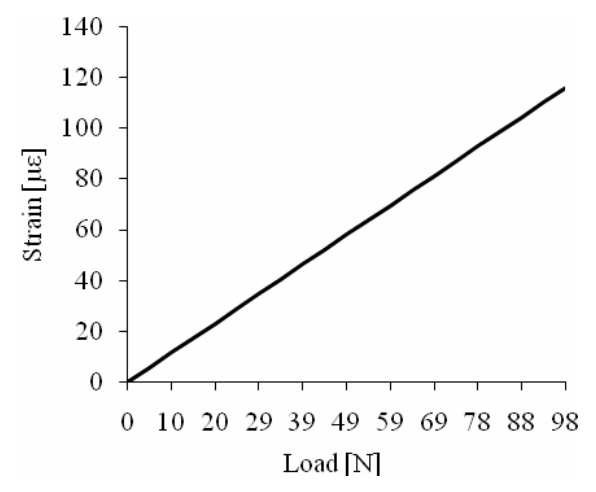

Fig. 4 Theoretical readout in $\mu \varepsilon$

\section{TEST BENCH RESULTS}

The resolution of $10 \mu \mathrm{V} / \mathrm{N}$ was verified by carrying out different load tests. Additionally, four prototypes were tested with different loads up to $100 \mathrm{~N}$. These tests were carried out on a test bench designed to simulate the conditions of the final setup. (Fig. 5) This setup included also small tensioning devices designed in the CERN vacuum group to pretension the steel cables. The readout was done using an Embedded Local Monitor Board (ELMB) ADC device [7], which was developed at CERN. Temperature probes (PT100) were installed in order to determine the remaining influence of temperature.

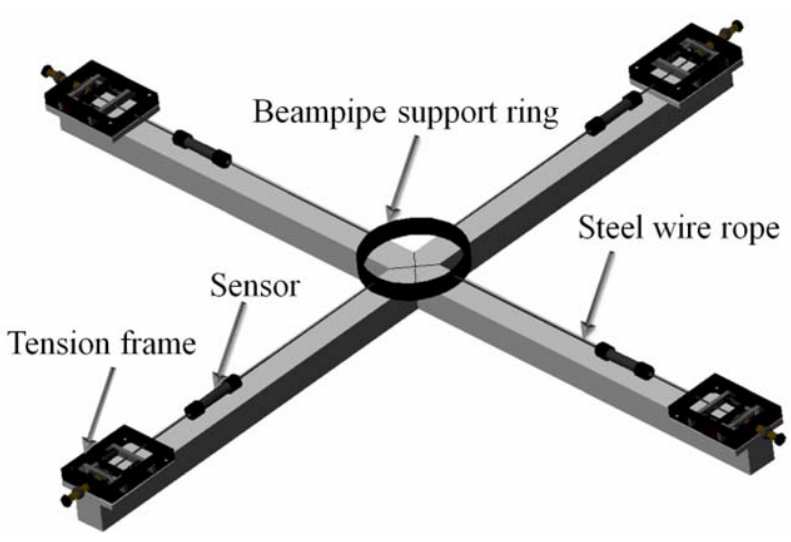

Fig. 5 Sensor test bench setup 
Figure 6 shows the remaining influence of temperature as measured during a test of an unloaded sensor. The function shows a strong linear correlation between the temperature reading and the output voltage. The readout range of $104 \mu \mathrm{V}$ $\left(\Delta \mathrm{T}=14.7^{\circ} \mathrm{C}\right)$ after one thermal cycle corresponds to a thermal elastic strain of $15.1 \mu \varepsilon$ or a force of $13 \mathrm{~N}$. This temperature effect of $7 \mu \mathrm{V} /{ }^{\circ} \mathrm{C}(1.2 \mu \varepsilon / \mathrm{N})$ will be compensated in the software.

Table 1: Sources of error

\begin{tabular}{ll}
\hline Analysed error sources \\
\hline 1 & Power supply stability \\
2 & Cabling and grounding \\
3 & Measurement system \\
4 & Influence of humidity \\
5 & Influence of air pressure \\
6 & Temperature gradients \\
7 & Active noise sources \\
8 & Other environmental influences \\
\hline
\end{tabular}

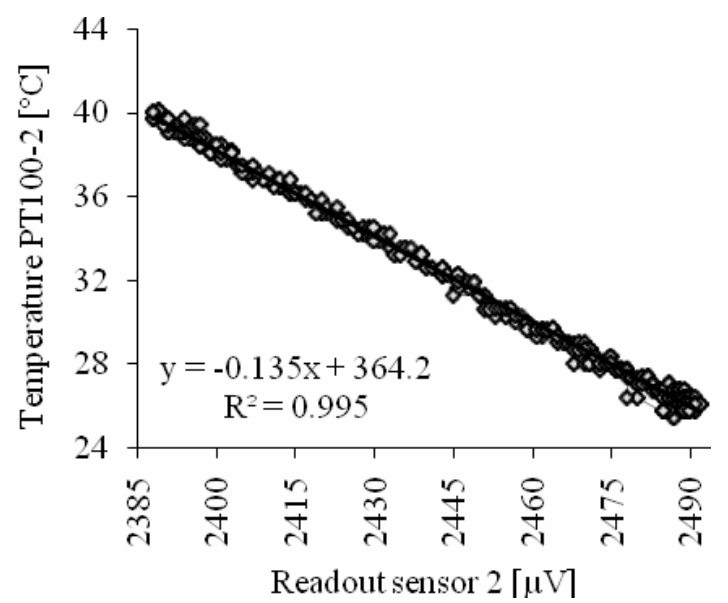

Fig. 6 Temperature influence

As the sensors will be used during the whole life cycle of the experiment it was necessary to prove their long term stability. The first long duration tests have shown a correlated drift in the four measured probes. In order to optimize and reduce this source of error, a time-consuming signal noise and drift analyses were required. The analysed sources of error are listed in Table 1. The power supply input voltage variation was approximately $\pm 1 \mathrm{mV}$ which corresponds to an absolute sensor error of $1 \mu \mathrm{V}$. Analyses of humidity and air pressure influences showed no correlation with the signal drift.
Different cable types were tested in order to improve the long duration stability. It was observed that great care was required for grounding and shielding the components in order to minimize external electromagnetic interference [11]. Figure 7 presents the results from a long duration test with a braided shield cable. The signal range is set to higher than $10 \mu \mathrm{V}$. This corresponds to the expected stability in the readout resolution of $1 \mathrm{~N}$. Figure 8 presents the correlation between the temperature and bridge offset during a 96 hour stability test. The result shows a linear correlation between the two read values. The readout range is set to higher than $10 \mu \mathrm{V}$. The influence of temperature correlates with the short duration test presented in Figure 6 and is in accord with the same value of 7 $\mu \mathrm{V} /{ }^{\circ} \mathrm{C}(1.2 \mu \varepsilon / \mathrm{N})$.

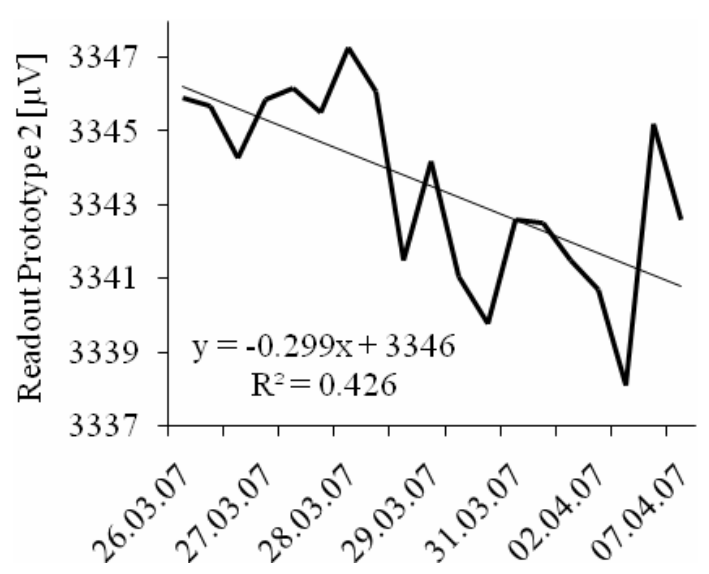

Fig. 7 Long duration stability test, Sensor 1

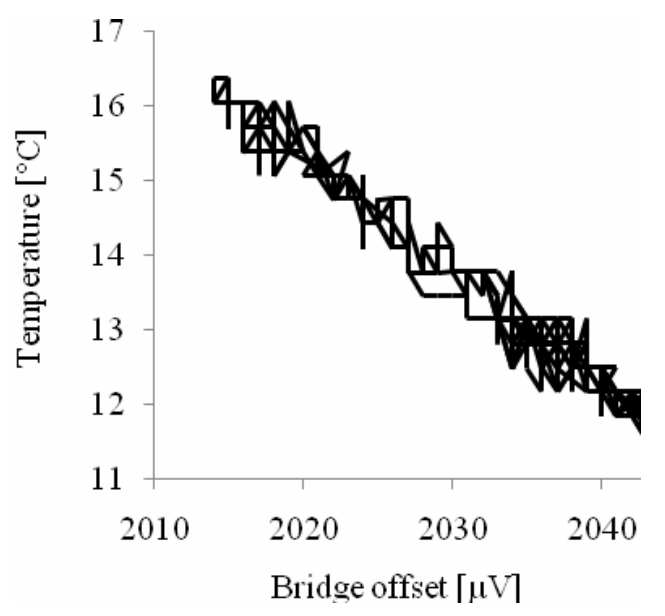

Fig. 8 Readout voltage, Sensor 2, F = $0 \mathrm{~N}$ 


\section{DISCUSSION AND CONCLUSION}

Using strain gauges is a standard method. It has been shown that the development of a highly sensitive sensor system for special applications like the ALICE beampipe monitoring demands a careful selection of components. In order to limit the multiple scattering of particles on their way from the interaction point to the detector small sensor size was one of the most important criteria. Special environmental conditions preclude industrial solutions. In order to achieve the required long duration stability, it was necessary to reduce the amount of noise and drift effects. This has been achieved by careful grounding and shielding. This results in an absolute system resolution of better than $1 \mathrm{~N}$.

\section{REFERENCES}

[1] ALICE Collaboration (2003, March). Technical design report. Retrieved March 12, 2006, from http://alice.web.cern.ch/Alice/TDR/

[2] Riegler, W. (2007, February). Beam pipe alignment, fixation, deformation mini-review. In Presentation in the weekly ALICE integration and service meeting. CERN, Geneva.

[3] CERN (2004, December). Large hadron collider project general information. Retrieved June 20, 2006, from http://lhc.web.cern.ch/lhc/general/gen info.htm

[4] ALICE Collaboration (2006). Physics performance report, Volume II. CERN, Geneva. Retrieved March 3, 2006, from

http://alice.web.cern.ch/Alice/ppr/web/PPRVIICurrentV ersion.html
[5] Tallman, C.R. (1972, January). Review and status of radiation effects studies on strain gages. New Mexico: Los Alamos Scientific Laboratory. (LA-DC--72-1344; CONF-721012--2)

[6] Lackner, F., Riegler, W., Kopetz, H., Osanna, P. H. (2006). A novel solution for various monitoring applications at CERN. Measurement Science Review 6(3), 27-31.

[7] Cook, J. R., Thomas, J. (2005, February). ELMB128 documentation. CERN, Geneva. Retrieved March 15, 2007, from http://elmb.web.cern.ch/ELMB/elmb.html

[8] VISHAY (2005, January). Strain gauge thermal output and gage factor variation with temperature. Technical note (Tech Note TN-504-1, Document Number: 11054)

[9] VISHAY, Strain gauge guide. Type 032UW. Retrieved January 30, 2007, from

http://www.vishay.com/brands/measurements_group/gu ide/500/gages/032uw.htm

[10] VISHAY, Strain gauge measurement technology. Formulas and Tables. Retrieved January 9, 2007, from http://www.vishay.com/strain-gages/knowledge-baselist/technotes-list/

[11] VISHAY (2005, January). Noise control in strain gage measurements. Technical note (Tech Note TN-501-2, Document Number: 11051) 